\title{
CONSIDERATIONS TO APPROACH MEMBRANE BIOFOULING IN MICRO- BIAL FUEL CELLS
}

\author{
SZABOLCS SZAKÁCS ${ }^{* 1}$ AND PÉTER BAKONYI ${ }^{1}$ \\ ${ }^{1}$ Research Institute on Bioengineering, Membrane Technology and Energetics, University of Pannonia, \\ Egyetem u. 10, 8200 Veszprém, HUNGARY
}

\begin{abstract}
Among bioelectrochemical systems, those referred to as microbial fuel cells (MFCs) are widely implemented for wastewater management and simultaneous recovery of electrical energy. MFCs are fundamentally assisted by bacterial populations, mostly mixed cultures to be more exact that, after oxidizing the substrate, are capable of facilitating the passage of electrons to an electron acceptor, usually the anode. However, certain undesired bacterial strains often colonize not only the electrode but the membrane separator over time and cause severe biofouling. The membrane is an architectural element of many MFCs and determines the efficiency of the system. In this paper, this issue is overviewed briefly and some considerations concerning how to approach the problem are presented.
\end{abstract}

Keywords: microbial fuel cell, membrane, oxygen mass transfer, biofouling

\section{Introduction}

Bioelectrochemical systems, including Microbial Fuel Cells (MFCs), are often installed with a physical separator such as a membrane as illustrated in Fig. 1 [1].

The membrane, which separates the anode from the cathode, should enable the adequate migration of ions (in this case, cations such as protons) between the electrodes to ensure the MFC continues to produce electricity [2]. Furthermore, the membrane should function as a barrier against the crossover effect of substances to avoid the loss of the substrate (which normally is injected into the anode chamber in order to feed the species of electroactive bacteria shown in Table 1 living on a biofilm on the electrically-conductive anode surface) and penetration of dissolved oxygen from the aerated cathode chamber to the anaerobic anode chamber [3].

In addition to these requirements which are associated with the physical and chemical properties of the material, the membranes should be relatively affordable. Another point that needs to be addressed is the stability of the membrane, which can be influenced by the complex chemical environment of the bulk phases (anolyte in the anode chamber, catholyte in the cathode chamber) in an MFC and microbiological phenomena [5]. Altogether, these effects may cause fouling of the membrane during its operation, moreover, when the underlying mechanism is associated with the metabolism and/or growth of microorganisms, the term "biofouling" is more appropriate [6]. In summary, various membranes can be evaluated

\footnotetext{
*Correspondence: szakacs.szabolcs@mk.uni-pannon.hu
}

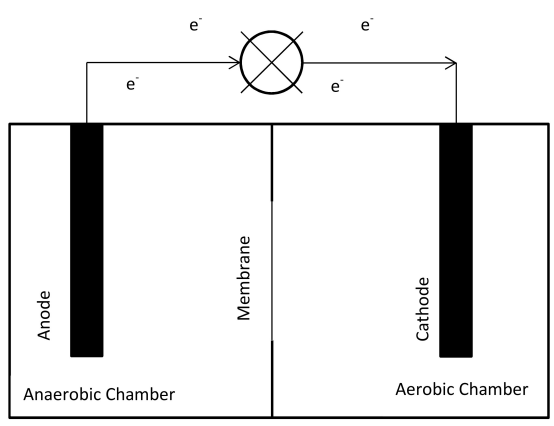

Figure 1: Scheme of an MFC

and ranked based on the characteristics of the membrane materials (typically but not exclusively fabricated from polymers) and their observed behavior during MFC operation which can be monitored by various electrochemical measurements, e.g., recording the cell voltage, as presented in Fig. 2.

\section{Membranes and biofouling in MFCs - The potential role of oxygen mass trans- fer}

In accordance with the previous section, the membrane separator divides the anaerobic anode chamber from the aerobic cathode chamber [7]. Therefore, it is reasonable to assume that the actual microbial communities developing on the anode and the membrane have completely different structures and relationships with gaseous oxygen. From the literature, it can be concluded with a good degree of certainty that the electrochemically active bacteria 
Table 1: Electroactive species of bacteria and their oxygen tolerance [4]

\begin{tabular}{ll}
\hline Species & Oxygen tolerance \\
\hline E. coli & facultatively anaerobic https://bacdive.dsmz.de/strain/4907 \\
facultatively anaerobic & https://img.jgi.doe.gov/cgi-bin/m/main.cgi?section= \\
& TaxonDetail\&page=taxonDetail\&taxon_oid=637000258 \\
& strict anaerobe https://bacdive.dsmz.de/strain/5792 \\
Geobacter sulfurreducens & strict anaerobe https://bacdive.dsmz.de/strain/5791 \\
Geobacter metallireducens & strict anaerobe https://bacdive.dsmz.de/strain/4004 \\
Desulfobulbus propionicus & strict anaerobe https://bacdive.dsmz.de/strain/17672 \\
Geothrix fermentans & facultatively anaerobic https://bacdive.dsmz.de/strain/13703 \\
Paracoccus pantotrophus & strict anaerobe https://bacdive.dsmz.de/strain/1819 \\
Rhodopseudomonas palustris DX-1
\end{tabular}

on the anode are either strict or facultative anaerobes as shown in Table 1 [4]. However, a considerable knowledge gap seems to exist concerning the populations attached to the surface of the membrane and the occurrence of biofouling. In contrast, it is reasonable to suppose that these membrane-bound colonies and biofilms are more tolerant of dissolved oxygen due to the technically direct and long-lasting contact with this substance. In general, the oxygen flux across a membrane in MFCs is described by the oxygen transfer coefficient which can be calculated by $[8,9]$

$$
k_{\mathrm{O}}=-\frac{V}{A t} \ln \left[\frac{\left(C_{0}-C\right)}{C_{0}}\right]
$$

where $k_{\mathrm{O}}$ denotes the oxygen transfer coefficient $\left(\mathrm{cm}^{3} / \mathrm{cm}^{2} \mathrm{~s}\right), V$ stands for the volume of liquid $\left(\mathrm{cm}^{3}\right)$, $A$ represents the surface area of the membrane $\left(\mathrm{cm}^{2}\right)$, $C_{0}$ refers to the saturation oxygen concentration $\left(\mathrm{mol} / \mathrm{dm}^{3}\right), C$ is the actual oxygen concentration measured $\left(\mathrm{mol} / \mathrm{dm}^{3}\right)$ and $t$ denotes the time of the measurement (s); and

$$
k_{\mathrm{O}}=\frac{D_{\mathrm{O}}}{L}
$$

where $D_{\mathrm{O}}$ stands for the oxygen diffusion coefficient $\left(\mathrm{cm}^{2} / \mathrm{s}\right)$ and $L$ represents the thickness of the membrane (cm).

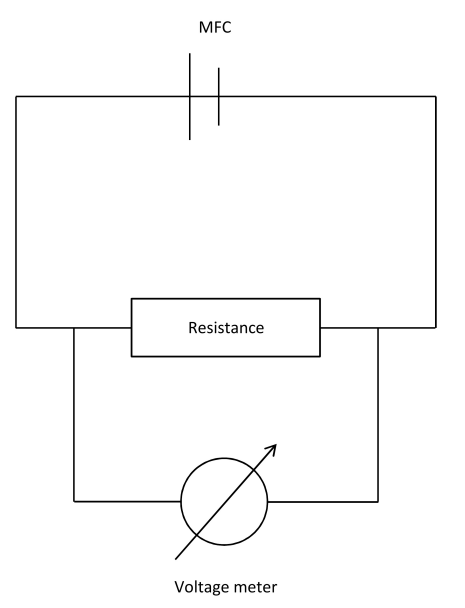

Figure 2: Schematic diagram of the MFC
Therefore, it is worth examining which strains colonize the membrane and how these mixed communities vary depending on ko. Even though some previous papers have demonstrated the use of various microscopic imaging techniques based on visual observations to study these biofouling layers on the surface of membranes [10-12], qualitative and quantitative feedback to highlight "what type of" and "how many" microbes can coexist is scarce. As a result, experimental methodology involving the apparatus of modern molecular biology, e.g. DNA-based identification, should be encouraged and implemented to answer such questions [13].

\section{Conclusions}

The capability of membranes to permeate dissolved oxygen in microbial fuel cells is key. On the one hand, reduced oxygen transport membranes (OTMs) are likely to maintain the typically less oxygen tolerant, electroactive bacteria located on the surface of the anode in a good condition. On the other hand, oxygen mass transfer through the membrane is expected to affect the biofouling of the separator and thus, how microbial communities respond to changes in material properties, in particular ko, needs to be understood. The assessment of membranes with different values of ko should be carried out relative to Nafion, which is by far the most broadly employed polymer for benchmarking studies [14].

\section{Acknowledgement}

This work was supported by the National Research, Development and Innovation Office (NKFIH, Hungary) under grant number FK 131409 and GINOP-2.3.2-15-201600016 Excellence of strategic R+D workshops, entitled "Development of modular, mobile water treatment systems and waste water treatment technologies based on University of Pannonia to enhance growing dynamic export of Hungary" (2016-2020) 


\section{REFERENCES}

[1] Leong, J. X.; Daud, W. R. W.; Ghasemi, M.; Liew, K. B.; Ismail, M.: Ion exchange membranes separators in microbial fuel cells for bioenergy conversion: A comprehensive review. Renew. Sustain. Energy Rev., 2013, 28, 575-587 DOI: 10.1016/j.rser.2013.08.052

[2] Daud, S. M.; Kim, B. H.; Ghasemi, M.; Daud, W. R. W.: Separators used in microbial electrochemical technologies: Current status and future prospects. Bioresour. Technol., 2015, 195, 170-179 DOI: 10.1016/j.biortech.2015.06.105

[3] Bakonyi, P.; Koók, L.; Kumar, G.; Tóth, G.; Rózsenberszki, T.; Nguyen, D. D.; Chang, S. W.; Zhen, G.; Bélafi-Bakó, K.; Nemestóthy, N.: Architectural engineering of bioelectrochemical systems from the perspective of polymeric membrane separators: A comprehensive update on recent progress and future prospects. J. Memb. Sci., 2018, 564, 508-522 DOI: 10.1016/j.memsci.2018.07.051

[4] Sharma, V.; Kundu, P. P.: Biocatalysts in microbial fuel cells. Enzyme Microb. Technol., 2010, 47(5), 179-188 DOI: 10.1016/j.enzmictec.2010.07.001

[5] Koók, L.; Bakonyi, P.; Harnisch, F.; Kretzschmar, J.; Chae, K.-J.; Zhen, G.; Kumar, G.; Rózsenberszki, T.; Tóth, G.; Nemestóthy, N.; Bélafi-Bakó, K.: Biofouling of membranes in microbial electrochemical technologies: Causes, characterization methods and mitigation strategies. Bioresour. Technol., 2019, 279, 327-338 DOI: 10.1016/j.biortech.2019.02.001

[6] Noori, Md. T.; Ghangrekar, M. M.; Mukherjee, C. K.; Min, B.: Biofouling effects on the performance of microbial fuel cells and recent advances in biotechnological and chemical strategies for mitigation. Biotechnol. Adv., 2019, 37(8), 107420 DOI: 10.1016/j.biotechadv.2019.107420

[7] Patil, S. A.; Gildemyn, S.; Pant, D.; Zengler, K.; Logan, B. E.; Rabaey, K.: A logical data representation framework for electricity-driven bioproduction processes. Biotechnol. Adv., 2015, 33(6), 736-744 DOI: 10.1016/j.biotechadv.2015.03.002
[8] Chae, K. J.; Choi, M.; Ajayi, F. F.; Park, W.; Chang, I. S.; Kim, I. S.: Mass transport through a proton exchange membrane (Nafion) in microbial fuel cells. Energy and Fuels, 2008, 22(1), 169-176 DOI: 10.1021/ef700308u

[9] Kim, J. R.; Cheng, S.; Oh, S.-E.; Logan, B. E.: Power generation using different cation, anion, and ultrafiltration membranes in microbial fuel cells. Environ. Sci. Technol., 2007, 41(3), 1004-1009 DOI: 10.1021/es062202m

[10] Venkatesan, P. N.; Dharmalingam, S.: Effect of cation transport of SPEEK - Rutile $\mathrm{TiO}_{2}$ electrolyte on microbial fuel cell performance. J. Memb. Sci., 2015, 492, 518-527 DOI: 10.1016/j.memsci.2015.06.025

[11] Angioni, S.; Millia, L.; Bruni, G.; Tealdi, C.; Mustarelli, P.; Quartarone, E.: Improving the performances of Nafion ${ }^{\mathrm{TM}}$-based membranes for microbial fuel cells with silica-based, organically-functionalized mesostructured fillers. J. Power Sources, 2016, 334, 120-127 DOI: 10.1016/j.jpowsour.2016.10.014

[12] Mokhtarian, N.; Ghasemi, M.; Daud, W. W. R.; Ismail, M.; Najafpour, G.; Alam, J.: Improvement of microbial fuel cell performance by using nafion polyaniline composite membranes as a separator. $J$. Fuel Cell Sci. Technol., 2013, 10(4), 041008 DOI: 10.1115/1.4024866

[13] Saratale, R. G.; Saratale, G. D.; Pugazhendhi, A.; Zhen, G.; Kumar, G.; Kadier, A.; Sivagurunathan, P.: Microbiome involved in microbial electrochemical systems (MESs): A review. Chemosphere, 2017, 177, 176-188 DOI: 10.1016/j.chemosphere.2017.02.143

[14] Rahimnejad, M.; Bakeri, G.; Ghasemi, M.; Zirepour, A.: A review on the role of proton exchange membrane on the performance of microbial fuel cell. Polym. Adv. Technol., 2014, 25(12), 1426-1432 DOI: $10.1002 /$ pat.3383 